\title{
The role of AUF1 in thyroid carcinoma progression
}

\author{
Bogusz Trojanowicz ${ }^{1,2}$, Lars Brodauf ${ }^{1}$, Carsten Sekulla ${ }^{1}$, Kerstin Lorenz $^{1}$, \\ Rainer Finke ${ }^{2}$, Henning Dralle ${ }^{1}$ and Cuong Hoang-Vu ${ }^{1}$
}

\author{
AG Experimentelle and Chirurgische Onkologie, Universitätsklinik und Poliklinik für ${ }^{1}$ Allgemein-, Viszeral- und Gefäßchirurgie and \\ ${ }^{2}$ Kinderchirurgie, Martin-Luther Universität, Magdeburger Strasse 18, 06097 Halle/S, Germany \\ (Correspondence should be addressed to C Hoang-Vu; Email: hoang-vu@medizin.uni-halle.de)
}

\begin{abstract}
AUF1/heterogeneous nuclear ribonucleoprotein D is an adenylate-uridylate-rich elements (AREs) -binding protein, which regulates the mRNA stability of many genes related to growth regulation, such as proto-oncogenes, growth factors, cytokines, and cell cycle-regulatory genes. Several studies demonstrated AUF1 involvement in the processes of apoptosis, tumorigenesis, and development by its interactions with ARE-bearing mRNAs. We report here that AUF1 may be involved in thyroid carcinoma progression. Investigations on thyroid tissues revealed that cytoplasmic expression of AUF1 in malignant tissues was increased when compared with benign thyroid tissues. In thyroid carcinoma cell lines, AUF1 was mostly detectable in the nucleus; however, in dividing cells, its increased production was also observed in the cytoplasm. We found AUF1 in complexes with ARE-bearing mRNAs, previously described to be crucial for proliferation and cell cycle of thyroid carcinoma. Total or exon-selective knockdown of AUF1 led to growth inhibition accompanied by induction of cell cycle inhibitors and decreased levels of cell cycle promoters. Our data demonstrate the existence of a complex network between AUF1 and mRNAs encoding proteins related to cell proliferation. AUF1 may control the balance between stabilizing and destabilizing effects, both of which are exerted on cell cycle machinery in thyroid carcinoma. Although we cannot exclude participation of other factors, thyroid carcinoma may recruit cytoplasmic AUF1 to disturb the stability of mRNAs encoding cyclin-dependent kinase inhibitors, leading to uncontrolled growth and progression of tumor cells. Thus, AUF1 may be considered as a new, additional marker for thyroid carcinoma.
\end{abstract}

Endocrine-Related Cancer (2009) 16 857-871

\section{Introduction}

The control of stability of many labile mRNAs is one of the critical mechanisms involved in post-transcriptional gene regulation in mammalian cells. Complex differences between normal and neoplastic cells are often related to differential mRNA expression, including genes that are essential for cell division, immune response, and tumorigenesis (Zhang et al. 1997). This regulation is largely exerted through the interaction of RNA-binding proteins (RBPs) with adenylate-uridylate-rich elements (ARE) contained in their $3^{\prime}$ untranslated region (UTR). AREs are pentamer repeats of AUUUA or oligo(U) sequences found in many transcripts encoding proto-oncogenes (c-fos, c-jun, c-myc, and egr-1), growth factors (vascular endothelial growth factor (VEGF), epidermal growth factor (EGF), insulin-like growth factor, and transforming growth factor), cytokines (interleukins and interferons), and cell cycle regulatory proteins $(\mathrm{p} 16, \mathrm{p} 21, \mathrm{p} 27$, cyclin A1, B1, D1, E2, and Cdk 2 and 6; Chen \& Shyu 1995). The list has considerably increased thanks to genomesequencing programs (Bakheet et al. 2001). Many RBPs have been described, which selectively recognize these sequences and modulate their translation and/or stability (Ross 1995, Lal et al. 2004), including $\mathrm{Hu}$ proteins (HuB, HuC, $\mathrm{HuD}$, and $\mathrm{HuR}), \mathrm{BRF} 1$, TIAR, TIA-1, KSRP, TTP, and AUF1 (Zhang et al. 1993, Park-Lee et al. 2003, Gherzi et al. 2004, Fenger-Gron et al. 2005, Lopez de Silanes et al. 2005, Suswam et al. 2005). Two AREs have been studied most extensively: AUF1, which is related to degradation of target mRNAs and HuR, which 
promotes stabilization of several transcripts by enhancing their stability, altering their translation, or performing both functions (Loflin et al. 1999, Brennan \& Steitz 2001).

AUF1 heterogeneous nuclear ribonucleoprotein D (hnRNPD), which causes transcript destabilization, is expressed as a family of four protein isoforms designated by their apparent molecular masses as p37, p40, p42, and p45, which arise by differential splicing of a single transcript (Ehrenman et al. 1994, Buzby et al. 1996). Some differences in the activity of various AUF1 isoforms are reported, but they generally enhance the degradation of target mRNAs in connection with ubiquitin and/or a proteasome complex (Chen et al. 2001, Laroia et al. 2002, Moraes et al. 2003).

AUF1 was first described with an activity that could accelerate degradation of c-myc mRNA in a cell-free system (Brewer 1991). However, in cells capable of proliferation such as fetal hepatocytes and adult lymphocytes, where AUF1 levels are much higher compared with adult hepatocytes, it could protect c-myc mRNA from decay (Lafon et al. 1998). Current data in transgenic mice showed that overexpression of AUF1 followed by deregulation of c-myc, c-fos, and c-jun led to the development of sarcomas with strong cyclin D1 expression. Accumulation of this cell cycle regulator favors increased cell division and tumorigenesis, which has been described in various neoplasias (Hosokawa \& Arnold 1998, Gouble et al. 2002). Non-small cell lung carcinoma cells treated with prostaglandin $\mathrm{A}_{2}$, an experimental anti-cancer agent, revealed decreased levels of cyclin D1, whose mRNA turnover was regulated by AUF1 (Lin et al. 2000). In malignant melanoma cells, reduced levels of AUF1 promoted IL-10 overexpression, which led tumor cells to evade the immune system, and protected them from apoptosis (Brewer et al. 2003). Another involvement of AUF1 during apoptosis was demonstrated in leukemia cells exposed to UVC irradiation, where binding of hnRNPD to bcl-2 mRNA enhanced its turnover (Lapucci et al. 2002). In senescenced cells, which exhibit higher levels of cyclin D1 and p21, and reduced levels of cyclin A1, B1, and c-fos, AUF1 was identified as a critical mediator of senescence events connected with p16 mRNA turnover (Wang et al. 2005).

Recent studies examining AUF1 expression in murine lung tumors have revealed that its cytosolic expression was increased in benign and malignant neoplasias, and correlated with growth rate both in vitro and in vivo (Blaxall et al. 2000). These data suggest that AUF1 could be an important effector and/or modulator of gene expression in the processes of carcinogenesis or proliferation.
In this study, we investigated the influence of AUF1 on ARE-regulated cell cycle modulators, previously described to be crucial for thyroid carcinoma progression. We also determined whether AUF1 localization is related to thyroid carcinoma. Finally, by employing total or exon-selective AUF1 knockdown, we investigated its role in the cell cycle and on the proliferation of thyroid carcinoma.

\section{Materials and methods}

\section{Tissues}

A total of 55 thyroid tissues, including 13 goiter tissues, 13 adenoma tissues, 14 follicular thyroid carcinomas (FTCs), eight papillary thyroid carcinomas (PTCs), and seven undifferentiated thyroid carcinomas (UTCs), were collected from patients at the Department of Surgery, University of Halle, by surgical resection (Table 1). This study was approved by the ethical committee of the Martin Luther University, Faculty of Medicine, and all patients gave written consent.

\section{Cell cultures and RNA interference}

Human thyroid carcinoma cell lines FTC-133, FTC-236, and FTC-238 (follicular) and 8505C, HTh74, C-643, and SW-1736 (undifferentiated) were cultured in DMEM/F12 medium supplemented with $1.125 \mathrm{~g} / \mathrm{l}$ sodium carbonate, $10 \% \mathrm{FCS}$, and $100 \mu \mathrm{g} / \mathrm{ml}$ streptomycin and penicillin. BC-PAP (papillary) and 8305C (undifferentiated) cells were cultured in RPMI 1640 medium supplemented with $0.85 \mathrm{~g} / \mathrm{l}$ sodium carbonate, 10\% FCS and antibiotics as described above. All mentioned cell lines were grown in humidified incubator at $37^{\circ} \mathrm{C} / 5 \% \mathrm{CO}_{2}$.

For AUF1 siRNA analysis, selected cell lines FTC133, BC-PAP, and 8505C representing three different types of thyroid carcinoma were plated in 6-well plates $\left(1.5 \times 10^{5}\right.$ cells pro well) and cultured overnight. Thereafter, siRNAs were transfected at final concentrations of $100 \mathrm{nM}$ in the presence of serum-free OptiMEM (Invitrogen) medium using Lipofectamine 2000 (Invitrogen) as the carrier. The siRNA sequence targeting exon 2 was 5'-GCA GCG ACG GCA CAG CGG G, exon $35^{\prime}$-GAU CCU AUC ACA GGG CGA U-3', and exon $75^{\prime}$-CUG GAA CCA GGG AUA UAG. Nonsilencing, randomized sequence 5'-AAT TCT CCG AAC GTG TCA CGT-3 not matching any known human gene was used at $100 \mathrm{nM}$ as a control. Analyses were performed $72 \mathrm{~h}$ after transfection.

For shRNA experiments, FTC-133 cells were transfected with $1 \mu \mathrm{g}$ pSUPER.neo+GFP vector 
Table 1 Immunohistochemistry results for AUF1 in thyroid tissue specimens

\begin{tabular}{|c|c|c|c|c|}
\hline \multirow[b]{2}{*}{ No. } & \multirow[b]{2}{*}{ Tissue } & \multirow[b]{2}{*}{ PTNM } & \multicolumn{2}{|c|}{ AUF1 } \\
\hline & & & Cytoplasm & Nucleus \\
\hline 1 & Goiter & & 3 & 7 \\
\hline 2 & Goiter & & 5 & 4 \\
\hline 3 & Goiter & & 7 & 6 \\
\hline 4 & Goiter & & 7 & 8 \\
\hline 5 & Goiter & & 2 & 6 \\
\hline 6 & Goiter & & 2 & 5 \\
\hline 7 & Goiter & & 1 & 6 \\
\hline 8 & Goiter & & 2 & 6 \\
\hline 9 & Goiter & & 2 & 6 \\
\hline 10 & Goiter & & 1 & 6 \\
\hline 11 & Goiter & & 2 & 7 \\
\hline 12 & Goiter & & 3 & 8 \\
\hline 13 & Goiter & & 2 & 5 \\
\hline 14 & Adenoma & & 6 & 5 \\
\hline 15 & Adenoma & & 4 & 4 \\
\hline 16 & Adenoma & & 5 & 6 \\
\hline 17 & Adenoma & & 6 & 4 \\
\hline 18 & Adenoma & & 3 & 5 \\
\hline 19 & Adenoma & & 7 & 7 \\
\hline 20 & Adenoma & & 7 & 8 \\
\hline 21 & Adenoma & & 8 & 6 \\
\hline 22 & Adenoma & & 7 & 7 \\
\hline 23 & Adenoma & & 10 & 6 \\
\hline 24 & Adenoma & & 7 & 6 \\
\hline 25 & Adenoma & & 6 & 7 \\
\hline 26 & Adenoma & & 6 & 8 \\
\hline 27 & FTC & pT4NxM1 & 8 & 1 \\
\hline 28 & FTC & pT2NOMx & 6 & 1 \\
\hline 29 & FTC & pT3NxM1 & 6 & 1 \\
\hline 30 & FTC & pT4N1M1 & 9 & 2 \\
\hline 31 & FTC & pT4NOMx & 8 & 2 \\
\hline 32 & FTC & pT3NxM0 & 7 & 2 \\
\hline 33 & FTC & pT2N1Mx & 8 & 3 \\
\hline 34 & FTC & pT2No & 9 & 4 \\
\hline 35 & FTC & pT3NOMO & 8 & 4 \\
\hline 36 & FTC & pT3N0M1 & 8 & 1 \\
\hline 37 & FTC & pT4NOMO & 8 & 1 \\
\hline 38 & FTC & pT3N1M0 & 7 & 1 \\
\hline 39 & FTC & pT3NoMo & 8 & 2 \\
\hline 40 & FTC & pT4N1M0 & 9 & 1 \\
\hline 41 & PTC & pT2NOMO & 8 & 2 \\
\hline 42 & PTC & pT4N1M0 & 7 & 2 \\
\hline 43 & PTC & pT2NOMO & 8 & 5 \\
\hline 44 & PTC & pT4NOMx & 9 & 4 \\
\hline 45 & PTC & pT1N1M0 & 8 & 6 \\
\hline 46 & PTC & pT1NOMO & 10 & 6 \\
\hline 47 & PTC & pT4N1Mx & 7 & 5 \\
\hline 48 & PTC & pT4N1Mx & 6 & 3 \\
\hline 49 & UTC & pT4NxMx & 9 & 1 \\
\hline 50 & UTC & pT3N0M1 & 6 & 1 \\
\hline 51 & UTC & pT4NxMx & 7 & 2 \\
\hline 52 & UTC & pT3N1Mx & 8 & 3 \\
\hline 53 & UTC & pT4N2Mx & 11 & 5 \\
\hline 54 & UTC & pT4 & 8 & 4 \\
\hline 55 & UTC & pT3N1M1 & 10 & 7 \\
\hline
\end{tabular}

(Oligoengine, Seattle, WA, USA) bearing sequencetargeting exon 3 used in transient RNAi experiments. Lipofectamine 2000 was used as a carrier. Control cells received plasmid alone. FTC-133 transfectants producing shRNAs targeting AUF1 and control cells were selected employing $800 \mu \mathrm{g} / \mathrm{ml}$ of geneticin. Knockdown efficiency was assessed by western-blot analysis. All experiments were repeated at least three times.

\section{Immunochemistry}

Thyroid carcinoma cell lines FTC-133, BC-PAP, and 8505C were seeded on thermanox plates and let grown in normal medium for 3 days. Freshly cut cryoembedded serial $6 \mu \mathrm{m}$ sections of all thyroid tissues and thyroid carcinoma cell lines were washed with PBS and fixed in a 1:4 mixture of $3 \% \mathrm{H}_{2} \mathrm{O}_{2}$ in ice cold $90 \%$ methanol for $20 \mathrm{~min}$. After washing twice with PBS, cells were incubated overnight at $4{ }^{\circ} \mathrm{C}$ with the rabbit polyclonal antibody against AUF1 (Millipore, Schwalbach, Germany) diluted 1:1000 with Dako Antibody Diluent (Dako, Glostrup, Denmark). Negative control sections were exposed to the secondary antibody only and processed as described below. After $3 \times 10 \mathrm{~min}$ washing in PBS, cells were incubated for $30 \mathrm{~min}$ with a 1:1000 dilution of biotinylated goat anti-rabbit secondary antibody followed by incubation with an avidin-biotin-peroxidase complex. After $3 \times 10 \mathrm{~min}$ washing in PBS, specific immunostaining was visualized with diaminobenzidine chromogenic solution (1:50). Finally, cells were lightly counterstained with Mayer's hematoxylin and photographed under light microscope (Axioplan 2, Zeiss, Jena, Germany). Fluorescent AUF1 staining was performed on microscope slides. Briefly, the cells were fixed with $4 \%$ formaldehyde solution in PBS for $10 \mathrm{~min}$. After $3 \times 10 \mathrm{~min}$ washing in PBS, the cells were incubated with previously mentioned AUF1 antibody overnight. Goat anti-rabbit IgG rhodamineconjugated (Millipore) antiserum was used to visualize fluorescent AUF1 staining.

All immunostained tissue sections were examined by two independent reviewers. For better quantification of specific immunostaining, planimetric measurement of immunoreactive cell clusters and tissue parts was evaluated semi-quantitatively using an Axioplan light microscope (Zeiss) by two independent investigators blinded to the histological diagnosis. Planimetric evaluations on immunostained specimens were also performed with the Zeiss KS300 software and the cytoplasm-nucleus relationship of immunopositive cells was determined. An AUF1 score was determined 
by multiplying two factors: overall staining intensity of the slide and specific cytoplasm or nuclear staining. In overall staining, the slides were evaluated according to $0-3$ points scale, where 0 means negative staining and 3 the strongest staining. The points for specific cytoplasm or nuclear staining were calculated as follows: $0,0-10 \%$ negative; $1,10-30 \%$ low expression; 2, 30-50\% moderate expression; 3, 50-80\% high expression; $4, \geq 80 \%$ very high expression.

\section{Messenger ribonucleoprotein immunoprecipitation}

Messenger ribonucleoprotein immunoprecipitation (IP) was performed as previously (Liao et al. 2005) with some modifications. Cytoplasmic lysates from FTC-133, BC-PAP, and 8505C cells were supplemented with RNAse OUT (Invitrogen), protease inhibitors (Roche), and then for preclearing incubated with A-Sepharose beads (Sigma) for $20 \mathrm{~min}$. Protein concentration was measured with Bradford assay. For IP of endogenous RNA-AUF1 complexes, A-Sepharose beads were precoated either with nonimmune rabbit IgG (Santa Cruz Biotechnology, Santa Cruz, CA, USA) or specific AUF1 antibody (Upstate, Dundee, UK) for $3 \mathrm{~h}$. Precleared lysates $(1.5 \mathrm{mg})$ were incubated with precoated beads overnight. Half of the beads were washed, mixed with loading buffer, boiled, and centrifuged. Supernatants were analyzed for the presence of AUF1 by western blotting. The other half of the beads were used for RNA extraction, followed by RNAse-free DNAse I (Roche) and proteinase K (Applied Biosystems/ Ambion, Austin, TX, USA) digestion. RNA was extracted using Trizol (Invitrogen) and overnight isopropanol precipitation. Reverse transcription (RT)-PCR was performed to examine RNAs associated with AUF1. RT-PCR products were visualized by $2 \%(\mathrm{w} / \mathrm{v})$ agarose gel electrophoresis, and cDNA of SKOS cells (human osteosarcoma cell line) was used as a positive control. AUF1 binding to selected mRNAs was verified three times.

\section{RT-PCR}

Total RNA was isolated using TriZol reagent (Invitrogen) according to the manufacturer's protocol. RT was performed using $1 \mu \mathrm{g}$ of total RNA and the Superscript II kit from Invitrogen as follows: $42{ }^{\circ} \mathrm{C}$ reaction temperature for $45 \mathrm{~min}, 95^{\circ} \mathrm{C}$ for $3 \mathrm{~min}$, and final step at $6{ }^{\circ} \mathrm{C}$. AUF1, p21, p27, p57, cyclin A1, cyclin B1, cyclin D1, cyclin D3, cyclin E1, Rb1, and $18 \mathrm{~S}$ PCR products were generated using following primers: AUF1, S-5'-TAA-GAA-CGA-GGA-GGATGA-AGG-3', AS-5'-TTC-CCA-TAA-CCA-CTCTGC-T-3'; p21, S-5'-AAG-ACC-ATG-TGG-ACCTGT-CA-3', AS-5'-GGC-TTC-CTC-TTG-GAG-AAGAT-3'; p27, S-5'-ATG-TCA-AAC-GTG-CGA-GTGTCT- $3^{\prime}$, AS-5'-TCT-GTA-GTA-GAA-CTC-GGGCAA-3'; p57, S-5'-TCG-CTG-CCC-GCG-TTT-GCGCA-3' ${ }^{\prime}$ AS-5'-CCG-AGT-CGC-TGT-CCA-CTT-CGG$3^{\prime}$; cyclin A1, S-5'-GCC-TGG-CAA-ACT-ATA-CTGTG-3', AS-5'-CTC-CAT-GAG-GGA-CAC-ACA-CA$3^{\prime}$; cyclin B1, S-5'-CGG-GAA-GTC-ACT-GGA-AACAT-3', AS-5'-AAA-CAT-GGC-AGT-GAC-ACC-AA$3^{\prime}$; cyclin D1, S-5'-TGC-GAG-GAA-CAG-AAGTGC-GAG-3', AS-5'-TGG-CAC-AGA-GGG-CAACGA-AG-3'; cyclin D3, S-5'-GAC-CTG-GCT-GCTGTG-ATT-GC-3', AS-5'-TCT-GTA-GGA-GTG-CTGGTC-TGG-C-3'; cyclin E1, S-5'-GAC-CGG-TATATG-GCG-ACA-CAA-G-3', AS-5'-TTC-AAG-GCAGTC-AAC-ATC-CAG-G-3'; Rb1, S-5'-CAG-ATGCAA-TTG-TTT-GGG-TG-3', AS-5'-TGA-ATG-GGCAGT-CAA-TCA-AA- $3^{\prime}$; and 18S, S-5'-GTT-GGTGGA-GCG-ATT-TGT-CTG-G-3', AS-5'-AGG-GCAGGG-ACT-TAA-TCA-ACG-C- $3^{\prime}$. Amplificates were analyzed on $2 \%$ agarose gels and stained with ethidium bromide. For image analyses, Kodak Image System 440 cf. (Eastman Kodak) was used and all experiments were performed in triplicates.

\section{Western-blot analysis}

Protein extracts were quantified using Bradford method and then separated on 10 and $12 \%$ polyacrylamide gels and blotted on PVDF membranes (Amersham Biosciences/GE Healthcare). Blocking was performed in 5\% nonfat milk powder or $5 \%$ BSA in $1 \times$ TBS/Tween $20(0.1 \%)$ for $1 \mathrm{~h}$. After thrice washing with $1 \times \mathrm{TBS} / \mathrm{Tw}$ ween 20 , the membranes were incubated overnight in AUF1 antiserum (1:20 000, Upstate), HuR 19F12 (1:1000, Invitrogen), p21 6B6 (1:500, BD Pharmingen, Heidelberg, Germany), Rb1 4H1 (1:500, Cell Signaling, Danvers, MA, USA), p27 F-8 (1:500), cyclin A1 H-432 (1:500), cyclin B1 GNS1 (1:500), cyclin D1 C-20 (1:500), and cyclin E1 HE12 (1:1000, Santa Cruz Biotechnology) in blocking buffer. After washing steps, the secondary goat anti-rabbit sc-2004 (1:40 000) and goat anti-mouse sc-2005 (1:20 000) antibodies were used (Santa Cruz Biotechnology). Specific protein bands were visualized using the ECL Detection Kit (Amersham Biosciences). Semi-quantitative evaluations of western blot were performed with Kodak Image Software 440 cf. (Eastman Kodak). Detection of specific protein bands was repeated at least three times. 


\section{Proliferation MTT assay and cell cycle}

In 96-well plates, 2500 FTC-133, BC-PAP, and 8505C cells were seeded and cultured with DMEM-F12 medium supplied with $10 \%$ FCS. The next day, the cells were transfected with $100 \mathrm{nM}$ siRNAs (targeting AUF1 exons and nonsilencing) diluted in OptiMem without serum. Lipofectamine 2000 was used as a carrier. After $24 \mathrm{~h}$, transfection medium was replaced and the cells were grown for additional $48 \mathrm{~h}$. For MTT assay, cells were then stained with MTT (3-[4,5dimethylthiazol-2-yl]-2,5-diphenyltetrazolium bromide) for $4 \mathrm{~h}$ at $37^{\circ} \mathrm{C}$ and shortly incubated with dimethyl sulfoxide (DMSO). Thereby, a colored formazan salt develops depending on the availability of mitochondrial NADH2 only in living, but not dead, cells. Optical density was measured with Tecan Elisa Reader (Tecan, Grödig, Austria). For FTC-133 stably expressing AUF1-targeting shRNAs, MTT assay was performed for $72 \mathrm{~h}$ in serum-free conditions. For cell cycle analysis, FTC-133, BC-PAP, and 8505C cells were synchronized in serum/leucine-free media for $36 \mathrm{~h}$, transfected with siRNA against AUF1 exon 3, and then released by serum addition (10\%). The cells were subjected for FACS analysis $72 \mathrm{~h}$ after transfection. All determinations were done in triplicates.

\section{Computational and statistical analysis}

Analysis of ARE regions of selected mRNAs was performed by employing CLC RNA Workbench software (CLS bio A/S, Katrinebjerg, Denmark). Statistical analysis was carried out with SPSS 12.0 software and all experimental parameters were calculated for statistical significance using ANOVA and Student's $t$-test. $P$ values of $<0.05$ were considered to indicate statistical significance.

\section{Results}

\section{Expression of AUF1 in thyroid tissues and thyroid carcinoma cells}

In order to answer the question whether the cellular localization of hnRNPD correlates with neoplasia, benign and malignant thyroid tissues were subjected to immunohistochemistry.

In these studies, stronger cytoplasmic AUF1 immunoreactivity was present in most thyroid carcinoma tissues representing FTC, PTC, and UTC when compared with goiter and adenoma. In contrast to malignant tissues, goiter and adenoma revealed weaker AUF1 immunoreactivity in cytoplasm, but much more intense in nucleus (Fig. 1A and Table 1).
Analyses of AUF1 expression in vitro were performed on the RNA level. We could show that all investigated thyroid carcinoma cell lines expressed AUF1 mRNA, however, with various levels of the different isoforms (Fig. 1B).

In studies concerning the possible role of AUF1 and its cellular distribution we employed immunocytochemistry. Thyroid carcinoma cell lines were seeded on thermanox plates or microscopic slides, fixed, and then stained with AUF1 antiserum. Microscopic investigations were mainly focused on cells undergoing cell division and showing strong AUF1 staining. We could demonstrate that dividing thyroid carcinoma cell lines revealed elevated cytoplasmic AUF1 levels as compared with surrounding cells (Fig. 2A and B). Thus, this observation indicates that the presence of increased AUF1 levels in cytoplasm of dividing thyroid carcinoma cells may affect their cell cycle and/or proliferation.

\section{AUF1 binds mRNAs of common cell cycle regulators}

Cytoplasm of thyroid carcinoma cells is a rich source of many labile mRNAs, which could be potential targets for AUF1. Additionally, many of these mRNAs encode proteins related to cell cycle or cell proliferation (Table 2). In order to investigate which mRNAs are associated with AUF1 in thyroid carcinoma cells, we performed IP reactions to isolate mRNA subsets bound to AUF1 using specific antibody. The nonspecific association of mRNAs with IP reagents was determined by parallel incubations with IgG (Fig. 3A). Detection of mRNAs in each thyroid cell line was achieved by RT followed by RT-PCR and agarose gel electrophoresis. As shown in Fig. 3B, AUF1 antibody precipitated several mRNAs, while control IgG did not precipitate these RNAs. We found that p21 and p27 mRNAs were associated with AUF1 in all cell lines investigated; however, the highest signal intensities were observed in FTC-133. Unfortunately, despite repeated attempts, we did not find the third member of Kip/Cip family, p57, to be associated with AUF1. Further analysis of AUF1 targets revealed its presence in complexes with cyclins. IP reactions from FTC-133 and BC-PAP revealed relative high amounts of cyclins $\mathrm{A} 1$ and D1, while in UTC cell line $8505 \mathrm{C}$, these mRNAs were not detectable. Cyclin B1 was found to be slightly bound to AUF1 in all cell lines investigated, while cyclin E1 could only be weakly amplificated in FTC-133. We did not find any cyclin D3 expression in all IP reactions. It is worth to notice that mRNAs of almost all cyclins investigated were not associated 
A
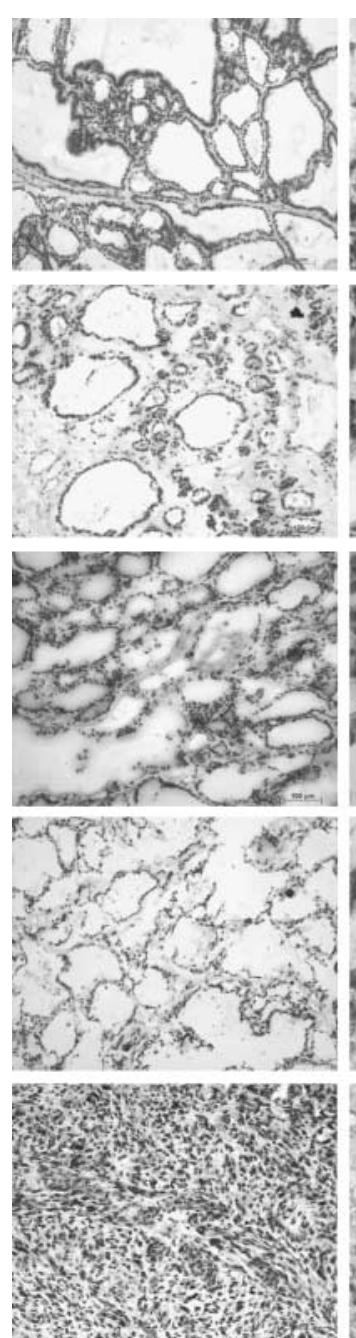
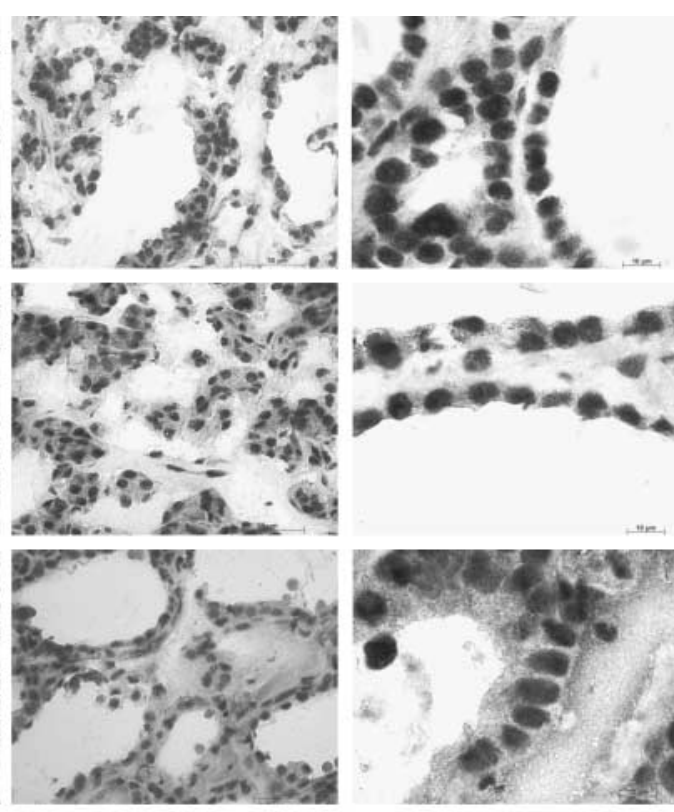

.
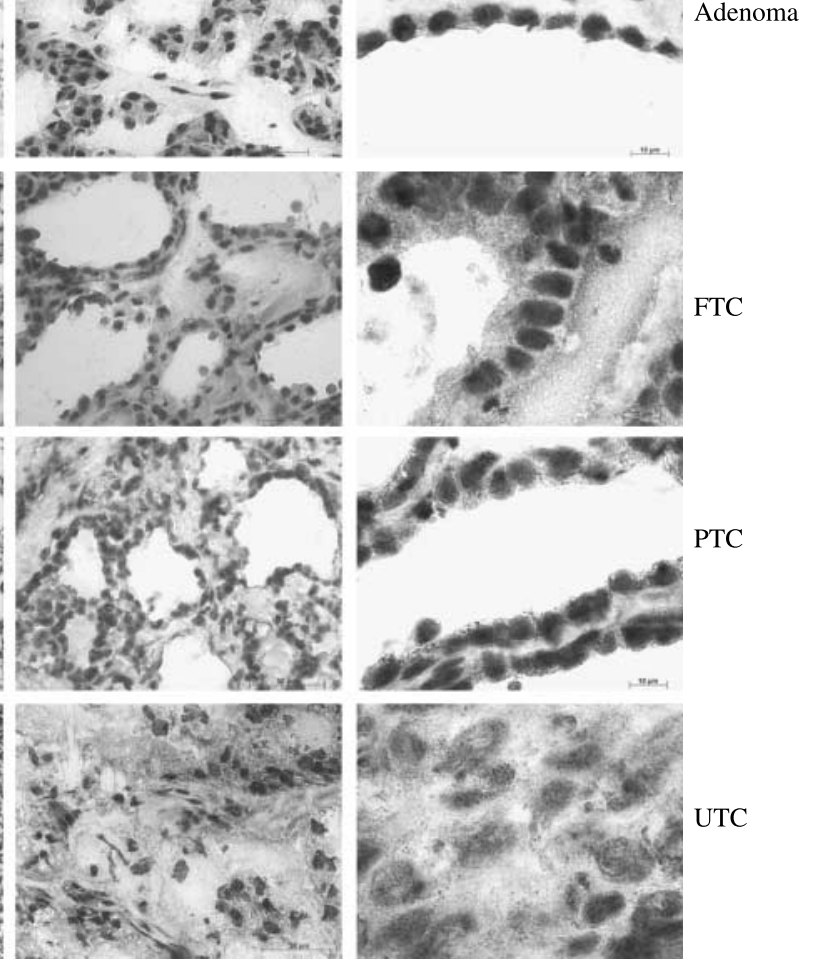

B

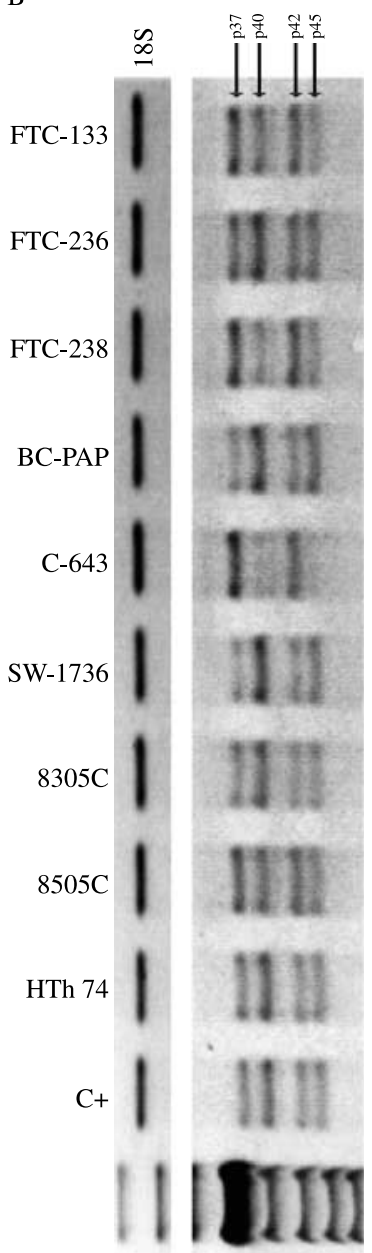

Figure 1 Analysis of AUF1 expression in thyroid carcinoma tissues and cell lines. (A) Immunohistochemistry for AUF1 in human thyroid tissues was performed on frozen, freshly cut serial $6 \mu \mathrm{m}$ cryosections using specific AUF1 antiserum (see also Table 1 and Materials and methods section for details). AUF1 staining is shown for goiter, adenoma, FTC, PTC, and UTC. Note strong, nuclear AUF1 immunoreactivity in goiter and adenoma tissues. (B) AUF1 mRNA expression in human thyroid cancer cell lines; the primers used detected four different AUF1 isoforms: p45, p42, p40 and p37 respectively. The BHY cell line (human oral squamous carcinoma), showing strong AUF1 mRNA expression, was used as a positive control $(C+)$. 18S transcripts were used to judge for equal cDNA amounts. Note that all cell lines expressed AUF1 mRNA, however, with various levels of the different isoforms.

with AUF1 in 8505C. Finally, we demonstrated strong interaction between AUF1 protein and mRNA of Rb1 in all investigated cells.

\section{Selective AUF1 exon down-regulation decreased proliferation of thyroid carcinoma cell lines}

The function of AUF1 in thyroid carcinoma progression is complicated to investigate by the existence of four isoforms and additionally by the fact that both destabilizing and stabilizing effects of AUF1 on
ARE-containing mRNAs have been reported. To differentially decrease selected AUF1 isoforms, we employed siRNAs targeting exon 3 contained in all four isoforms, exon 2 in isoforms p40AUF1 and p45AUF1, and exon 7, which is present in isoforms p42AUF1 and p45AUF1. In order to knockdown isoforms p40AUF1, p42AUF1, and p45AUF1 without affecting p37AUF1, we used a combination of siRNAs targeting exon 2 and exon 7. First, using western blot, we evaluated whether the selected siRNAs specifically decreased corresponding isoforms (Fig. 4A). 
A $\quad$ FTC-133

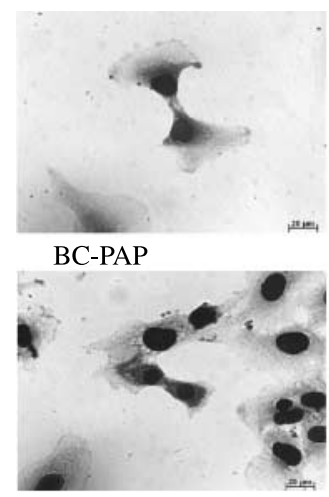

$8505 \mathrm{C}$

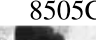

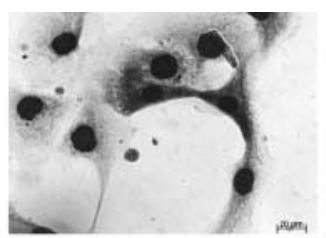
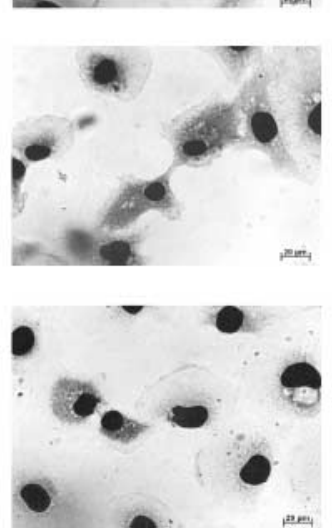

B FTC-133
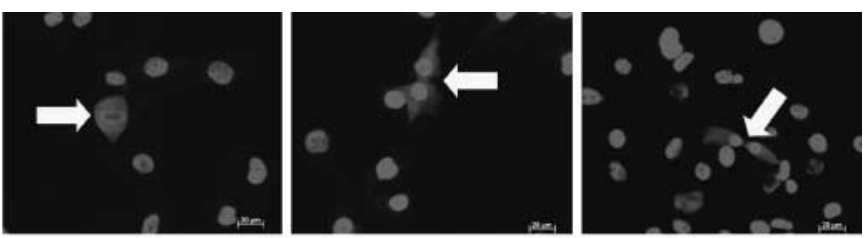

BC-PAP
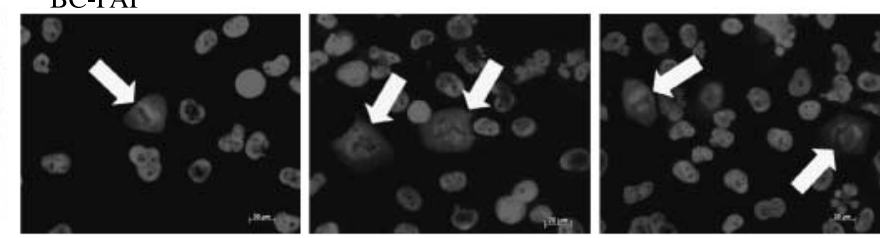

$8505 \mathrm{C}$
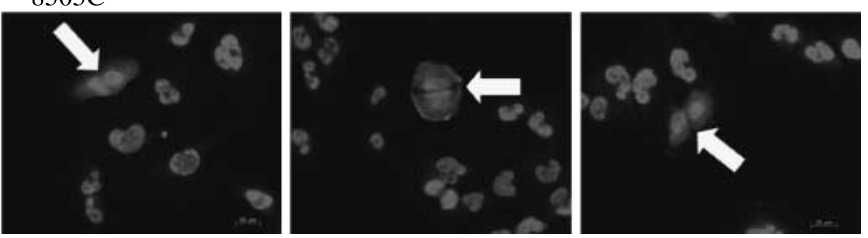

Figure 2 Cellular localization of AUF1 in thyroid carcinoma cells as performed by (A) diaminobenzidine staining and (B) immunofluorescence. (A) FTC-133, BC-PAP, and 8505C thyroid carcinoma cells were seeded on thermanox plates, fixed, and then stained with specific AUF1 antibody. (B) The same cell lines and primary anti-AUF1 antibody were used for fluorescence staining. In order to avoid background emission, the cells were seeded on glass microscopic slides. Secondary rhodamineconjugated antiserum was used to visualize fluorescent AUF1 staining. Note that AUF1 is mostly localized in nucleus and its cytoplasmic immunoreactivity is observed in FTC-133, BC-PAP, and 8505C currently undergoing cells division.

As expected, designed siRNAs specifically targeted AUF1 isoforms; however, RNA interference effects were weaker in BC-PAP cell line comparing with FTC133 or $8505 \mathrm{C}$. We could demonstrate that targeting of exon 2 decreased expressions of p40AUF1 and p45AUF1. Interference of exon 3 led to reduced expression of all AUF1 isoforms, and employing siRNA targeting exon 7 led to down-regulation of two upper isoforms p42AUF1 and p45AUF1. Finally, combination of two siRNAs interfering exons 2 and 7 specifically reduced three AUF1 isoforms p40AUF1,
p42AUF1, and p45AUF1, while isoform p37AUF1 remained unchanged (Fig. 4B). In order to investigate the influence of AUF1 knockdown on proliferation of thyroid carcinoma cell lines, FTC-133, BC-PAP, and $8505 \mathrm{C}$ with selectively decreased AUF1 isoforms were evaluated by employing proliferation MTT assay. As shown in Fig. 4C, each of siRNAs tested reduced proliferation of the cells; however, the most pronounced reduction was observed after silencing of all four AUF1 isoforms (by $~ 58 \%$ for FTC-133, 56\% for BC-PAP, and $\sim 76 \%$ for $8505 \mathrm{C}$ ). These results are

Table 2 Features of adenylate-uridylate-rich elements (ARE)-containing mRNAs related to cell cycle and proliferation investigated in this study; + indicates the presence of $A$ - or U-rich regions

\begin{tabular}{|c|c|c|c|c|c|c|c|}
\hline $\begin{array}{l}\text { ARE } \\
\text { sequence }\end{array}$ & $\begin{array}{l}\text { Length of } \\
3^{\prime} \text {-UTR (nt) }\end{array}$ & Adenine (\%) & Uridine (\%) & $\begin{array}{l}\text { No. of } \\
\text { AUUUA } \\
\text { motifs }\end{array}$ & $\begin{array}{c}\text { No. of } \\
\text { UUAUUUA } \\
\text { (U/A) (U/A) } \\
\text { nonamers }\end{array}$ & $\begin{array}{c}\text { No. of } \\
\text { AUUUA } \\
\text { motifs out of } \\
3^{\prime} \text {-UTR }\end{array}$ & $\begin{array}{l}\text { Presence of } \\
\text { A- or U-rich } \\
\text { regions }\end{array}$ \\
\hline p21 & 1552 & 20 & 26 & 3 & 0 & 0 & + \\
\hline p27 & 1345 & 34 & 33 & 7 & 0 & 0 & + \\
\hline p57 & 716 & 29 & 27 & 3 & 0 & 0 & + \\
\hline Cyclin A1 & 218 & 35 & 32 & 1 & 0 & 2 & + \\
\hline Cyclin B1 & 623 & 39 & 29 & 4 & 0 & 2 & + \\
\hline Cyclin D1 & 3208 & 29 & 25 & 7 & 0 & 0 & + \\
\hline Cyclin D3 & 1052 & 24 & 25 & 2 & 0 & 0 & + \\
\hline Cyclin E1 & 543 & 24 & 28 & 0 & 0 & 0 & + \\
\hline $\mathrm{Rb} 1$ & 1820 & 30 & 38 & 12 & 1 & 3 & + \\
\hline
\end{tabular}



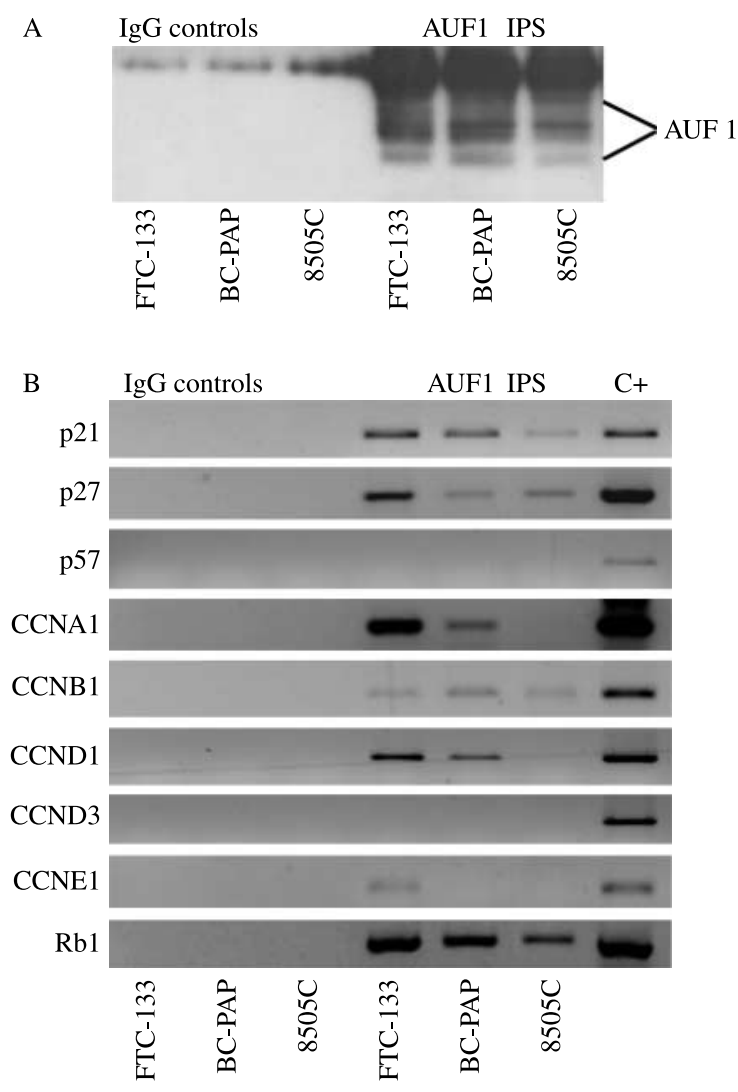

Figure $\mathbf{3}$ Immunoprecipitation of AUF1 mRNA complexes in thyroid carcinoma cell lines. Cytoplasmic protein lysates obtained from thyroid cancer cells were incubated with A-Sepharose beads precoated with AUF1 antibody. AUF1 mRNA complexes were separated from A-Sepharose beads. The presence of AUF1 and AUF1-bound mRNAs was analyzed by employing western blot and RT-PCR respectively.

(A) Western-blot analysis demonstrated AUF1 in cytoplasmic extracts of all cell lines investigated. No AUF1 immunoreactivity was detected in beads precoated with normal rabbit IgGs, which served as negative controls. (B) RT-PCR-based amplification of mRNAs found to be associated with cytoplasmic AUF1. Selected primers specific for cell cycle regulators involved in thyroid carcinoma progression were used. mRNA released from AUF1 mRNA complexes was reversely transcribed and then amplified with primers specific for selected mRNAs (see Materials and methods section for details). PCR products were visualized on $2 \%$ agarose gel. AUF1 was found in complexes with p21, p27, and cyclin B1 mRNAs in all cell lines analyzed. mRNAs of cyclin A1 and D1 were detectable in both differentiated thyroid carcinoma cell lines, while cyclin E1 was found in FTC-133 cells only. The presence of p57 and cyclin D3 mRNA in complexes with AUF1 could not be detected. cDNA of SKOS cells (human osteosarcoma cell line) was used as a positive control.

Experiments were repeated at least three times.

consistent with the previous studies demonstrating similar effects of AUF1 knockdown on proliferation of K562 (human chronic myeloid leukemia), THP-1 (human promonocytic leukemia), HeLa (human cervical carcinoma), and HT-29 (human colon carcinoma) cell lines (Liao et al. 2007). However, silencing of
p45AUF1, p42AUF1, and p40AUF1 isoforms simultaneously or separately induced weaker reduction in proliferation rates when comparing with experiment with silencing of exon 3 where additional knockdown of isoform p37AUF1 was induced. Thus, further experiments were performed by employing knockdown of all AUF1 isoforms. In order to investigate whether AUF1-knockdown-mediated, decreased proliferation rates are due to alteration in cell cycle profile, the cells were subjected for FACS analysis. As shown in Fig. 4D, total AUF1 interference, which led to lowest proliferation rates in MMT assay, also here induced markedly greater S and G2/M compartments.

The results of transient reduction of all AUF1 isoforms we verified by employing DNA sequence corresponding to siRNA were used against exon 3 . This sequence was cloned into shRNA-expressing vector and transfected into FTC-133 cell line possessing the highest proliferation rates. As shown in Fig. 5A and B, all clones (A13, A17, and A21) of FTC-133 stably expressing shRNAs clearly demonstrated knockdown of all AUF1 isoforms when comparing with wild-type cells or EGFP control (E19). Additionally, we found that AUF1 knockdown correlated with decreased levels of HuR, other AREbinding and stabilizing protein. Finally, as expected, the same clones tested for their growth properties revealed significantly reduced proliferation rates as demonstrated by MTT (Fig. 5E). Thus, based on these data, we hypothesized that AUF1 may affect the stability of genes related to cell cycle and cell proliferation. We focused further studies to investigate this AUF1 function.

\section{Decreased proliferation rates of thyroid carcinoma cell lines affected the expression of cyclin-dependent kinase inhibitors}

We found that also in thyroid carcinoma cell lines, AUF1 was able to bind mRNAs of Kip/Cip family of Cdk inhibitors p21 and p27; however, no binding of p57 was detectable. Kip/Cip family comprises p21, p27, and p57 inhibitors that are able to inhibit all cyclin-Cdk complexes. In most cell systems, their expression was induced by anti-proliferative signals and led to cell cycle arrest (el-Deiry et al. 1993, Polyak et al. 1994, Lee et al. 1995, Sherr \& Roberts 1995).

Protein and mRNA expression analysis performed on Kip/Cip family of Cdk inhibitors revealed that transient interference of all AUF1 isoforms led to affected expression pattern of p21 and p27 in all three cell lines analyzed (Fig. 6A-D). Investigations of p21 demonstrated its significantly increased expression in 

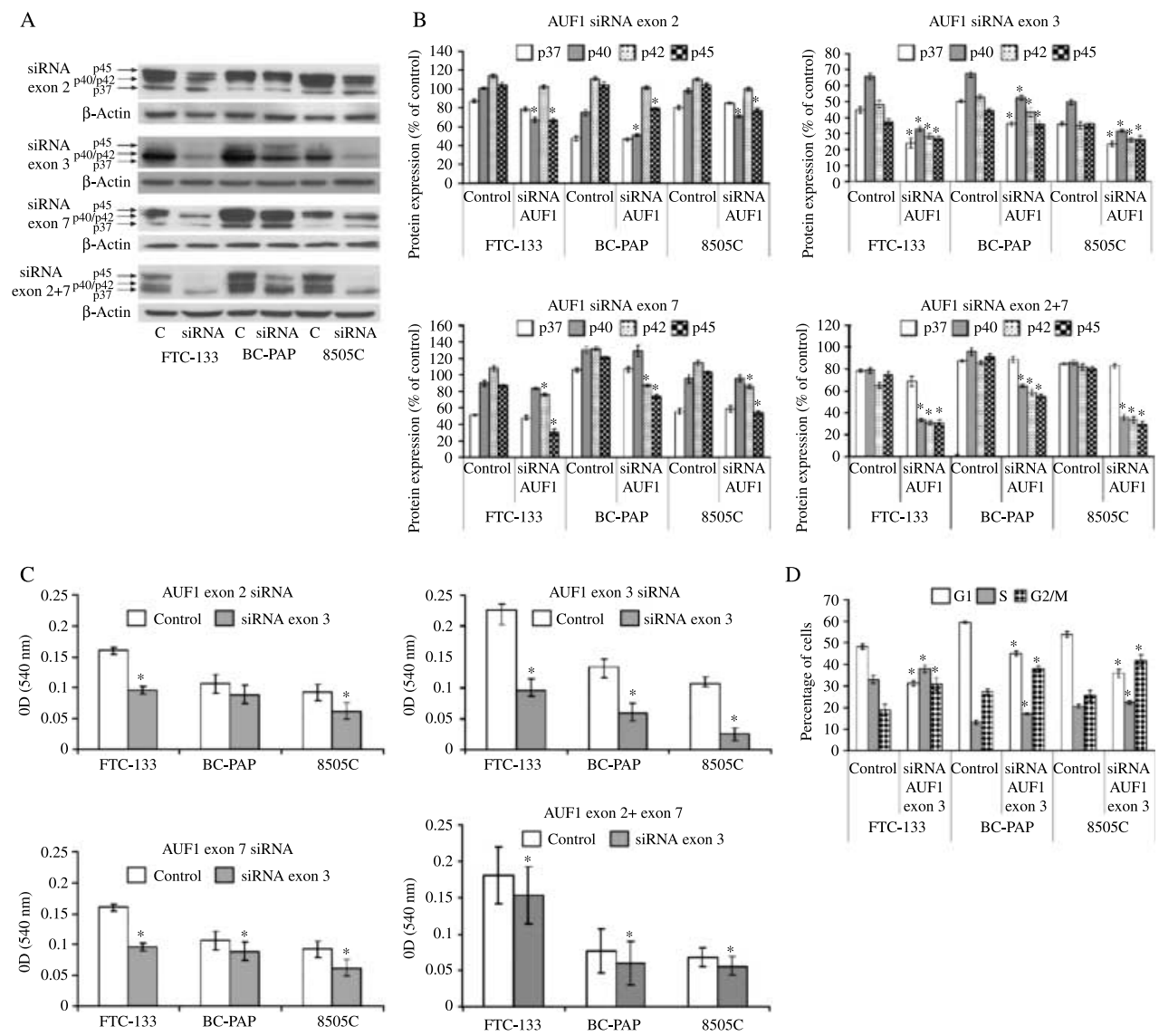

Figure 4 Analysis of cell cycle and proliferation after selective or total knockdown of AUF1 isoforms. FTC-133, BC-PAP, and 8505C cells were incubated with siRNAs targeting different AUF1 exons. Specific silencing of total AUF1 was mediated by knockdown of exon 3 contained in all four isoforms, exon 2 in isoforms p40AUF1 and p45AUF1, and exon 7 in isoforms p42AUF1 and p45AUF1. Combination of siRNAs targeting exon 2 and exon 7 respectively led to silencing of isoforms p40AUF1, p42AUF1, and p45AUF1, while p37AUF1 remained unaffected. Western-blot analysis, proliferation assay, and cell cycle analysis were performed $72 \mathrm{~h}$ after transfection. (A) Representative western-blotting results and (B) densitometric analysis of AUF1 expression are shown. The results represent the average of three independent experiments $\left({ }^{\star} P<0.05\right)$. Detection of $\beta$-actin was used as protein-loading control. (C) Proliferation of thyroid carcinoma cell lines after selective knockdown of AUF1 isoforms. FTC-133, BC-PAP, and 8505C cells were evaluated for their growth properties employing MTT assay. Selective or total AUF1 silencing noticeably decreased proliferation of the cells; however, the most pronounced growth inhibition was observed after interference of all AUF1 isoforms $\left({ }^{\star} P<0.05\right)$. Experiments were done in triplicates. (D) Analysis of cell cycle performed after total AUF1 knockdown. FTC-133, BC-PAP, and $8505 \mathrm{C}$ cells were synchronized by serum and leucine removal, transfected with siRNA targeting exon 3 , and then released by $10 \%$ serum addition. The cells were subjected for FACS analysis $72 \mathrm{~h}$ after transfection in order to determine their cell cycle profile. Bars represent the average profile of three independent experiments. Significant reduction in G1 and markedly increased $\mathrm{S}$ and $\mathrm{G} 2 / \mathrm{M}$ compartments are visible $\left({ }^{*} P<0.05\right)$.

AUF1 siRNA-treated FTC-133 and 8505C cell lines. In BC-PAP cells representing PTC, p21 mRNA and protein were only slightly elevated after AUF1 silencing. The second mRNA of Kip/Cip family demonstrated to be a target for AUF1 was p27. Expression of p27 in control FTC-133 cells was comparable with that of p21 experiment. Employing siRNA-targeting AUF1 noticeably increased p27 expression in FTC-133 and BC-PAP cells. Interestingly, AUF1 knockdown showed no effect on p27 mRNA and protein expression in $8505 \mathrm{C}$ cells.

\section{AUF1 knockdown led to dysregulation of cell cycle-related proteins}

To obtain additional information concerning the regulation of cell cycle-related proteins, further investigations were performed on cyclins A1, B1, $\mathrm{D} 1$, and E1, previously reported to be increased in extracts from human cancers and related to thyroid carcinoma (Hall \& Peters 1996, Sherr 1996, Lazzereschi et al. 1998, Ito et al. 2002). Westernblot analysis performed after AUF1 knockdown revealed decreased levels of cyclins crucial for cell 

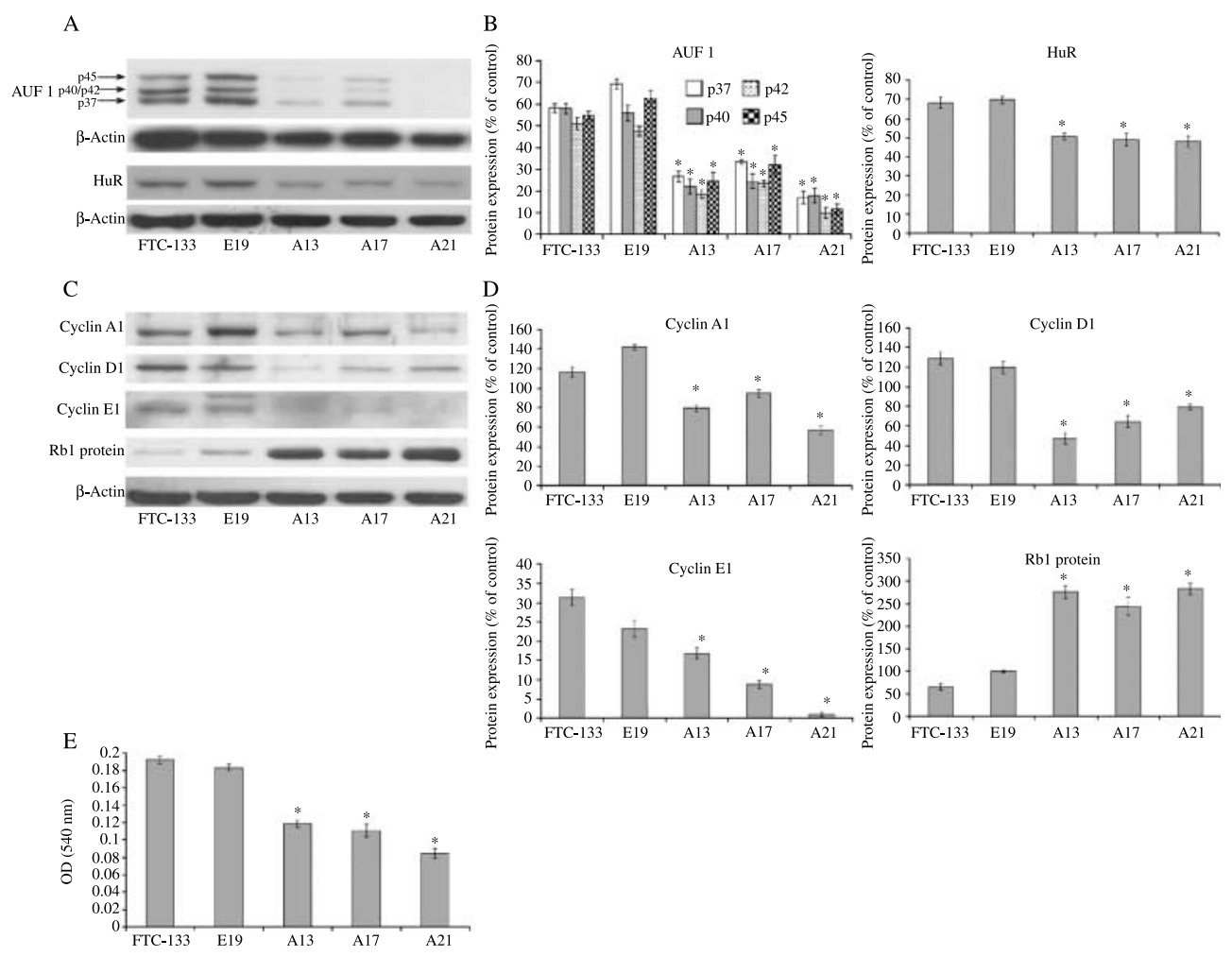

Figure 5 FTC-133 cells stably expressing reduced all AUF1 isoforms show decreased proliferation rates and expression of cell cycle-related proteins. (A) FTC-133 cells transfected with shRNA vector-targeting AUF1 exon 3 (A13, A17, and A21) produced noticeably decreased AUF1 and HuR levels as compared with EGFP controls (E19) or wild-type cells (FTC-133). Expression of both proteins was detected with specific AUF1 and HuR anti-sera. Representative western blots are shown and $\beta$-actin served as normalizing marker. (B) Western-blot bands were quantified and normalized to $\beta$-actin. Significant ( $P<0.05)$ reduction in all AUF1 isoforms and HuR protein is visible. (C) Protein expression analysis of selected cell cycle regulators. Lysates obtained from wild-type cells (FTC-133), EGFP (E19), and shRNA (A13, A17 and A21) transfectants were incubated with specific antibodies for cyclin A1, $\mathrm{D} 1, \mathrm{E} 1$, and Rb1 protein. Representative western blots are shown. (D) Protein expressions were quantified and normalized to $\beta$-actin. Significant $\left({ }^{\star} P<0.05\right)$ reduction in cyclins and increased levels of Rb1 protein are presented as the average of three independent experiments. (E) FTC-133 wild-type cells, EGFP controls (E19), and three AUF1 shRNA clones (A13, A17, and A21) were subjected for MTT proliferation assay for $72 \mathrm{~h}$. Significant $\left({ }^{\star} P<0.05\right)$ reduction in proliferation rates is visible as compared with corresponding controls.

proliferation (Fig. 6E and F). We could demonstrate that cyclin A1 strongly expressed in control FTC-133 was noticeably reduced after employing siRNAtargeting AUF1. Similar results were obtained for BC-PAP and 8505C cells. However, here control BC-PAP and 8050C cells expressed cyclin A1 much weaker when comparing with FTC-133. Interestingly, cyclin A1 was not found in complexes with AUF1 in 8505C cells, nevertheless was down-regulated after siRNA treatment. The next cell cycle regulator analyzed was cyclin B1. We showed that cyclin B1 mRNA was associated with AUF1 in all cell lines investigated. However, on protein level, it was expressed in control $8505 \mathrm{C}$ cells only and AUF1 knockdown noticeably decreased cyclin $\mathrm{B} 1$ production in this cell line. Expression of cyclin D1 was found to be reduced in all cell lines analyzed. Expression of cyclin E1 was only slightly decreased in FTC-133 cells, and also in this cell line mRNA of cyclin E1 was found to weakly associate with AUF1. We also found that AUF1 knockdown affected the expression of AREstabilizing protein HuR. We demonstrated significant reduction of this protein in FTC-133 and 8505C cells. It is worth to notice that also in previous studies, decreased levels of HuR resulted in reduced proliferation rates due to decrease in mRNA stability of cyclins A1 and B1 (Wang et al. 2000).

We could also demonstrate that AUF1 knockdown affected the production of tumor-suppressor retinoblastoma protein. Our computational analysis revealed that out of all mRNAs analyzed, Rb1encoding mRNA contains the highest number of AUUUA repeats. This could possibly result in strong AUF1-Rb1 interaction as demonstrated by our IP 
A

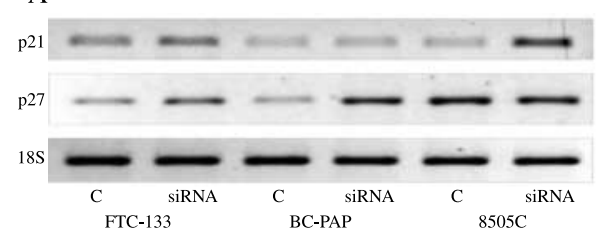

C

p2
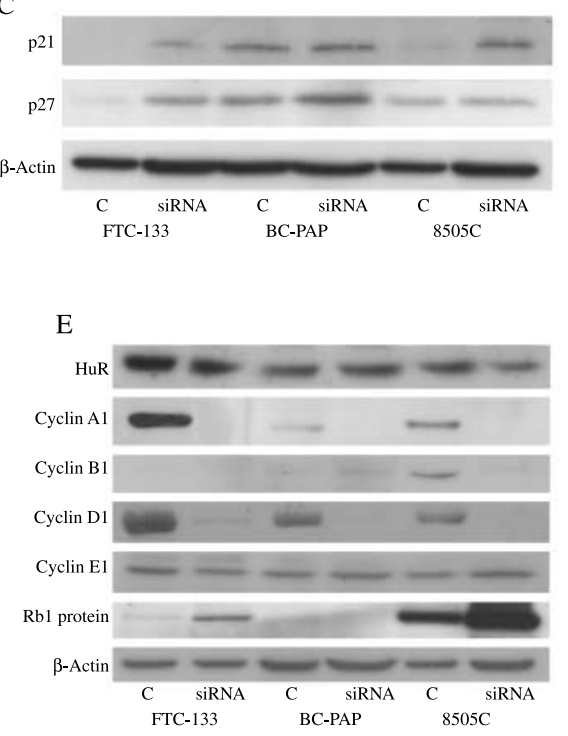

B

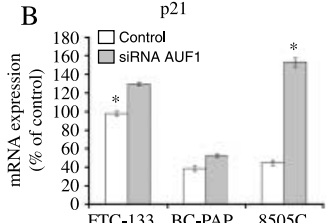

D

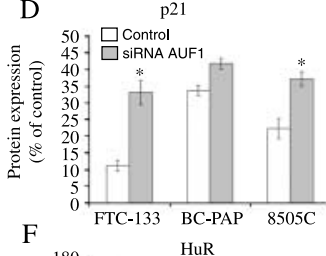

F 180
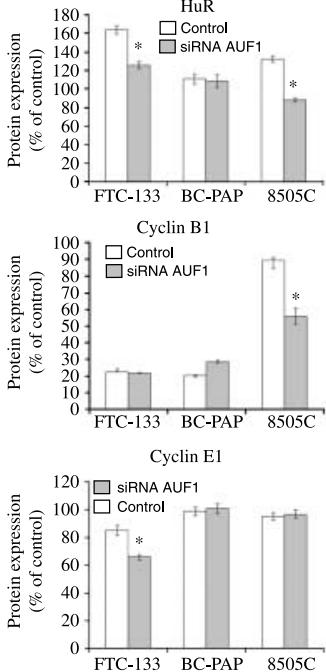
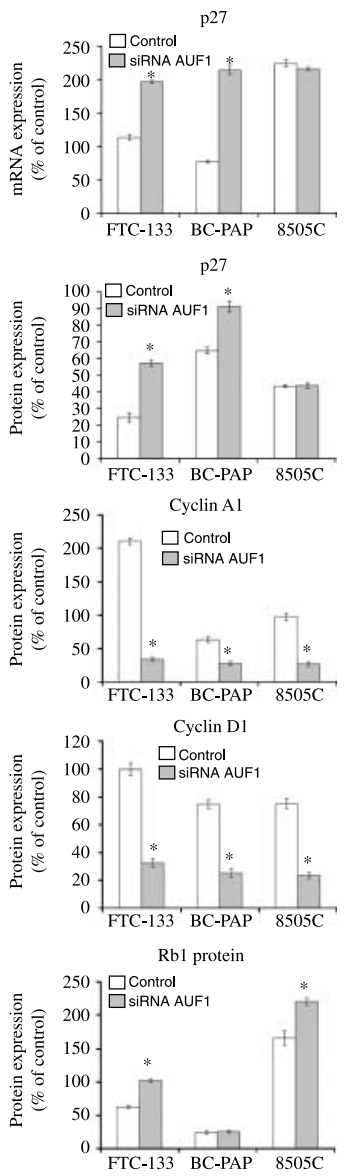

Figure 6 Analysis of cell cycle-related proteins after total AUF1 knockdown. Total RNAs or protein from control and AUF1 siRNAtreated FTC-133, BC-PAP, and 8505C cells were subjected for RT-PCR or western-blot analysis. (A) RT-PCR performed with primers specific for p21, p27, and 18S. Representative agarose gels are shown. (B) Quantification of RT-PCR results. Significant $\left({ }^{\star} P<0.05\right)$ up-regulation of p21 and p27 mRNA expression is noticeable. 18S served as normalizing marker. (C and E) Representative western blots performed with antibodies specific for p21, p27 and HuR, cyclins A1, B1, D1, E1, and Rb1 protein. $\beta$-Actin served as normalizing marker. ( $D$ and F) Quantification of western blot results. Note that p21 and p27 proteins correlated with mRNA expression. Significant reduction or up-regulation of particular protein is indicated $\left({ }^{\star} P<0.05\right.$ indicate significance).

experiments (Fig. 3B). Western-blot analysis revealed that retinoblastoma protein is noticeably increased in FTC-133 and 8505C cells, when AUF1 is knocked down. Interestingly, both in control- and siRNAtreated BC-PAP cells, expression of retinoblastoma protein was not detectable (Fig. 6E). Further analysis performed on FTC-133 transfectants with reduced AUF1 expression (Fig. 5A and B) revealed similar expression pattern of cell cycle- related proteins, demonstrated in transient AUF1 experiments. Also here long-term reduction of AUF1 resulted in decreased levels of ARE-stabilizing protein HuR, which correlated with significant down-regulation of cyclins A1, D1, and E1 and up-regulation of retinoblastoma protein when comparing with EGFP controls (E19) or wild-type FTC-133 cells (Fig. 5C and D).

\section{Discussion}

In our study, we provide the evidence that the AREbinding protein AUF1 participates in thyroid carcinoma progression. We found increased cytoplasmic AUF1 levels in dividing thyroid carcinoma cell lines and in most malignant thyroid carcinoma tissues. Using a RNAi model with transient and stable AUF1 knockdown, we demonstrated its involvement in thyroid carcinoma cell cycle and proliferation. Furthermore, we show that AUF1 interacts with mRNAs encoding cyclins and cyclin-dependent kinase inhibitors reported to be crucial for thyroid carcinoma progression.

Expression of AUF1 has already been demonstrated in several malignancies; however, its relationship with human thyroid carcinoma is novel. Previous data obtained from mouse tumor models indicate that 
most lung neoplastic tissues express increased cytoplasmic AUF1 levels when compared with normal lung tissues (Blaxall et al. 2000). Similar results were demonstrated for HuR, another ARE-binding protein, where its relative cytoplasmic abundance in the colon was lowest in the normal mucosa, moderately higher in adenomas, and highest in carcinomas (Lopez de Silanes et al. 2003). Other reports demonstrated that overexpression of hnRNPD led to dysregulation of several target mRNAs and promoted tumorigenesis (Gouble et al. 2002).

We demonstrated that AUF1 is expressed both in the cytoplasm and the nucleus of thyroid carcinoma and benign thyroid cells, however on different levels. We found that increased cytoplasmic expression of AUF1 correlated with neoplasticity, which is in agreement with previous studies (Blaxall et al. 2000); however, this was not demonstrated for thyroid carcinoma. The lowest cytoplasmic hnRNPD level was detectable in benign and adenoma tissues, and the highest in malignant tissues, including FTC, PTC, and UTC. Furthermore, dividing thyroid carcinoma cell lines revealed increased cytoplasmic AUF1 levels, as compared with surrounding cells. Such a dependency between cellular localization of AUF1 and proliferation status was already demonstrated for mammary gland tissue. In these studies, decreased AUF1 levels in the cytoplasm of mammary gland cells correlated with differentiation status, induction of milk production, and inhibition of proliferation (Nagaoka et al. 2007). It is worth to notice that in this study, a decreased proliferation rate was due to decreased AUF1 levels in the cytoplasm.

Since all investigated thyroid carcinoma cells already expressed AUF1, we thus aimed to study its role by RNA interference. We could show that selective or total knockdown of AUF1 isoforms decreased cell proliferation. We found that the most pronounced growth and cell cycle inhibition were obtained after knockdown of all isoforms. We observed that additional knockdown of AUF1p37 led to the strongest reduction in proliferation rates as compared with simultaneous or separate interference of other isoforms. However, whether the AUF1p37 isoform is crucial for increased proliferation of thyroid carcinoma cells requires its overexpression in further studies. This isoform has the strongest affinity for AREs binding in vitro and its overexpression was previously reported to induce tumors with high cellularity, rich vascularization, and commonly observed mitosis (Gouble et al. 2002). Furthermore, total AUF1 knockdown decreased the growth of several cancer cell lines, whereas its overexpression promoted proliferation (Wang et al. 2005, Liao et al. 2007).

We demonstrated that increased expression of the cyclin-dependent kinase inhibitors p21 and p27 correlated with reduced growth rates of thyroid carcinoma cell lines after AUF1 knockdown. We found that p21 mRNA and protein were elevated in all thyroid carcinoma cell lines analyzed. Transcriptional regulation of p21 expression has previously been shown to be positively regulated by three tumorsuppressor genes, p53 (el-Deiry et al. 1993), BRCA-1 (Somasundaram et al. 1997), and Rb1 (Decesse et al. 2001). We found that AUF1 knockdown followed by up-regulation of p21 expression led to increased production of $\mathrm{Rb} 1$ protein. In contrast to p53 and BRCA-1, demonstrated not to be the targets for AUF1 (data not shown), we showed that mRNAs of p21 and Rb1 interact with AUF1 and are regulated in an AUF1dependent manner. Also both proteins were already related to thyroid carcinoma progression. It was demonstrated that progressive loss of p21 and Rb1 protein was observed in differentiated and most malignant, poorly differentiated, or undifferentiated thyroid tissues as compared with benign thyroid lesions (Brzeziński et al. 2005, Melck et al. 2007). Moreover, retinoblastoma protein reconstitution in various human cancer cell lines suppressed tumorigenicity both in vitro and in vivo, while $\mathrm{Rb} 1$ knockdown led to increased proliferation rates of lung cancer cells (Li et al. 1996, Reed et al. 2006). We also showed that AUF1 interference led to up-regulation of p27 in differentiated thyroid carcinoma cell lines FTC-133 and BC-PAP. Reduced expression of p27 was reported in most poorly differentiated and UTCs, and the level of p27 protein decreased during tumor development and progression (Wang et al. 1998, Lloyd et al. 1999). Additionally, down-regulation of p27 was noted in PTCs with a tendency to lymph node metastases (Khoo et al. 2002, Karlidag et al. 2007).

We found that all AUF1-bound mRNAs contained A- or U-rich regions within their 3'-UTR; however, not all were stabilized or up-regulated when AUF1 was knocked down. We demonstrated that down-regulation of AUF1 led to decreased production of cyclins A1, B1, D1, and E1. On the other hand, these data correlate well with studies which reported increased levels of those proteins in most malignant thyroid tissues and their important role in thyroid carcinogenesis (Ito et al. 2002, Brzezianska et al. 2007), but not with a destabilizing function of AUF1. There are several possible scenarios in order to explain the behavior of these particular mRNAs in AUF1-mediated actions. It is possible that mRNAs of $\mathrm{p} 21, \mathrm{p} 27$, and $\mathrm{Rb} 1$, but not 
those of cyclins, may contain an additional signature motif particularly recognized by AUF1 and AUF1interacting proteins. In case of cyclins, it is also possible that AREs are not the only binding place for AUF1 and it can interact with determinants localized within the cyclins' coding region. Such an additional interaction can temporarily change the AUF1 function and, depending on interaction, affinity may lead to short time stabilization of the cyclins' mRNAs. AUF1 binding to coding determinants may block translation initiation of the cyclins' mRNA, leading to blockage of deadenylation and accumulation of these mRNAs (Mazan-Mamczarz et al. 2009). Some reports postulate the existence of at least two distinct mechanisms controlling AUF1-related mRNA degradation (Xu et al. 2001). In the case of cyclins, action of only one such mechanism may be not sufficient to disturb their stability. We can also not exclude the participation of other ARE-binding proteins, like HuR. We speculate that the stability of the cyclins' mRNA could be mostly regulated in a HuR-dependent manner, as demonstrated for cyclin A1 and cyclin B1 (Wang et al. 2000).

In conclusion, all these observations suggest that decreased AUF1 levels, which lead to dysregulation of cell cycle-related proteins and growth inhibition, could have beneficial effects on thyroid cancer. Although we cannot exclude the participation of other factors, we demonstrated that malignant thyroid cells may recruit cytoplasmic AUF1 in order to decrease the stability of cyclin-dependent kinase inhibitors and promote increased proliferation of the cells. Understanding how thyroid carcinoma achieves distinct regulation of the stability of various ARE-containing mRNAs remains an open challenge, but AUF1 may serve as a novel marker, helpful in answering this question.

\section{Declaration of interest}

The authors declare that there is no conflict of interest that would prejudice the impartiality of this scientific work.

\section{Funding}

This study was partly supported by Deutsche Forschungsgemeinschaft (DFG) and Deutsche Krebshilfe.

\section{Acknowledgements}

We would like to thank Ms Kathrin Hammje, Ms Anja Winkler, and Mr Rico Hoffmann for their excellent technical assistance in creation of this manuscript.

\section{References}

Bakheet T, Frevel M, Williams BR, Greer W \& Khabar KS 2001 ARED: human AU-rich element-containing mRNA database reveals an unexpectedly diverse functional repertoire of encoded proteins. Nucleic Acids Research 29 246-254.

Blaxall BC, Dwyer-Nield LD, Bauer AK, Bohlmeyer TJ, Malkinson AM \& Port JD 2000 Differential expression and localization of the mRNA binding proteins, AU-rich element mRNA binding protein (AUF1) and Hu antigen $\mathrm{R}$ (HuR), in neoplastic lung tissue. Molecular Carcinogenesis 28 76-83.

Brennan CM \& Steitz JA $2001 \mathrm{HuR}$ and mRNA stability. Cellular and Molecular Life Sciences 58 266-277.

Brewer G 1991 An A+U-rich element RNA binding factor regulates c-myc mRNA stability in vitro. Molecular and Cellular Biology 11 2460-2466.

Brewer G, Saccani S, Sarkar S, Lewis A \& Pestka S 2003 Increased interleukin-10 mRNA stability in melanoma cells is associated with decreased levels of A+U-rich element binding factor AUF1. Journal of Interferon \& Cytokine Research 23 553-564.

Brzezianska E, Cyniak-Magierska A, Sporny S, PastuszakLewandoska D \& Lewiński A 2007 Assessment of cyclin D1 gene expression as a prognostic factor in benign and malignant thyroid lesions. Neuro Endocrinology Letters 28 341-350.

Brzeziński J, Migodziński A, Toczek A, Tazbir J \& Dedecjus M 2005 Patterns of cyclin E, retinoblastoma protein, and p21Cip1/WAF1 immunostaining in the oncogenesis of papillary thyroid carcinoma. Clinical Cancer Research 11 1037-1043.

Buzby JS, Lee SM, Van Winkle P, DeMaria CT, Brewer G \& Cairo MS 1996 Increased granulocyte-macrophage colony-stimulating factor mRNA instability in cord versus adult mononuclear cells is translation-dependent and associated with increased levels of A+U-rich element binding factor. Blood 88 2889-2897.

Chen CY \& Shyu AB 1995 AU-rich elements: characterization and importance in mRNA degradation. Trends in Biochemical Sciences 20 465-470.

Chen CY, Gherzi R, Ong SE, Chan EL, Raijmakers R, Pruijn GJ, Stoecklin G, Moroni C, Mann M \& Karin M 2001 AU binding proteins recruit the exosome to degrade ARE-containing mRNAs. Cell 107 451-464.

Decesse JT, Medjkane S, Datto MB \& Crémisi CE 2001 $\mathrm{RB}$ regulates transcription of the $\mathrm{p} 21 / \mathrm{WAF} 1 / \mathrm{CIP} 1$ gene. Oncogene 20 962-971.

Ehrenman K, Long L, Wagner BJ \& Brewer G 1994 Characterization of cDNAs encoding the murine A + U-rich RNA-binding protein AUF1. Gene 149 315-319.

el-Deiry WS, Tokino T, Velculescu VE, Levy DB, Parsons R, Trent JM, Lin D, Mercer WE, Kinzler KW \& Vogelstein B 1993 WAF1, a potential mediator of p53 tumor suppression. Cell 75 817-825. 
Fenger-Gron M, Fillman C, Norrild B \& Lykke-Andersen J 2005 Multiple processing body factors and the ARE binding protein TTP activate mRNA decapping. Molecular Cell 20 905-915.

Gherzi R, Lee KY, Briata P, Wegmuller D, Moroni C, Karin M \& Chen CY 2004 KH domain RNA binding protein, KSRP, promotes ARE-directed mRNA turnover by recruiting the degradation machinery. Molecular Cell 14 571-583.

Gouble A, Grazide S, Meggetto F, Mercier P, Delsol G \& Morello D 2002 A new player in oncogenesis: AUF1/hnRNPD overexpression leads to tumorigenesis in transgenic mice. Cancer Research 62 1489-1495.

Hall M \& Peters G 1996 Genetic alterations of cyclins, cyclin-dependent kinases, and Cdk inhibitors in human cancer. Advances in Cancer Research 68 67-108.

Hosokawa Y \& Arnold A 1998 Mechanism of cyclin D1 (CCND1, PRAD1) overexpression in human cancer cells: analysis of allele-specific expression. Genes, Chromosomes \& Cancer 22 66-71.

Ito Y, Yoshida H, Nakano K, Takamura Y, Kobayashi K, Yokozawa T, Matsuzuka F, Matsuura N, Kuma K \& Miyauchi A 2002 Expression of G2-M modulators in thyroid neoplasms: correlation of cyclin A, B1 and cdc2 with differentiation. Pathology, Research and Practice 198 397-402.

Karlidag T, Cobanoglu B, Keles E, Alpay HC, Ozercan I, Kaygusuz I, Yalcin S \& Sakallioglu O 2007 Expression of Bax, p53, and p27/kip in patients with papillary thyroid carcinoma with or without cervical nodal metastasis. American Journal of Otolaryngology 28 31-36.

Khoo ML, Beasley NJ, Ezzat S, Freeman JL \& Asa SL 2002 Overexpression of cyclin D1 and underexpression of p27 predict lymph node metastases in papillary thyroid carcinoma. Journal of Clinical Endocrinology and Metabolism 87 1814-1818.

Lafon I, Carballe F, Brewer G, Poiret M \& Morello D 1998 Developmental expression of AUF1 and HuR, two c-myc mRNA binding proteins. Oncogene 16 3413-3421.

Lal A, Mazan-Mamczarz K, Kawai T, Yang X, Martindale JL \& Gorospe M 2004 Concurrent versus individual binding of HuR and AUF1 to common labile target mRNAs. EMBO Journal 23 3092-3102.

Lapucci A, Donnini M, Papucci L, Witort E, Tempestini A, Bevilacqua A, Nicolin A, Brewer G, Schiavone N \& Capaccioli S 2002 AUF1 is a bcl-2 A+U-rich elementbinding protein involved in bcl-2 mRNA destabilization during apoptosis. Journal of Biological Chemistry 277 16139-16146.

Laroia G, Sarkar B \& Schneider RJ 2002 Ubiquitindependent mechanism regulates rapid turnover of AU-rich cytokine mRNAs. PNAS 99 1842-1846.

Lazzereschi D, Sambuco L, Carnovale Scalzo C, Ranieri A, Mincione G, Nardi F \& Colletta G 1998 Cyclin D1 and cyclin $\mathrm{E}$ expression in malignant thyroid cells and in human thyroid carcinomas. International Journal of Cancer 76 806-811.
Lee MH, Reynisdottir I \& Massague J 1995 Cloning of p57KIP2, a cyclin-dependent kinase inhibitor with unique domain structure and tissue distribution. Genes and Development 9 639-649.

Li J, Hu SX, Perng GS, Zhou Y, Xu K, Zhang C, Seigne J, Benedict WF \& Xu HJ 1996 Expression of the retinoblastoma $(\mathrm{RB})$ tumor suppressor gene inhibits tumor cell invasion in vitro. Oncogene 13 2379-2386.

Liao B, Hu Y, Herrick DJ \& Brewer G 2005 The RNAbinding protein IMP-3 is a translational activator of insulin-like growth factor II leader-3 mRNA during proliferation of human K562 leukemia cells. Journal of Biology 280 18517-18524.

Liao B, Hu Y \& Brewer G 2007 Competitive binding of AUF1 and TIAR to MYC mRNA controls its translation. Nature Structural \& Molecular Biology 14 511-518.

Lin S, Wang W, Wilson GM, Yang X, Brewer G, Holbrook NJ \& Gorospe M 2000 Down-regulation of cyclin D1 expression by prostaglandin $\mathrm{A}_{2}$ is mediated by enhanced cyclin D1 mRNA turnover. Molecular and Cellular Biology 20 7903-7913.

Lloyd RV, Erickson LA, Jin L, Kulig E, Qian X, Cheville JC \& Scheithauer BW 1999 p27kip1: a multifunctional cyclin-dependent kinase inhibitor with prognostic significance in human cancers. American Journal of Pathology 154 313-323.

Loflin P, Chen Ch-YA \& Shyu A-B 1999 Unraveling a cytoplasmic role for hnRNP D in the in vivo mRNA destabilization directed by the AU-rich element. Genes and Development 13 1884-1897.

Lopez de Silanes I, Fan J, Yang X, Zonderman AB, Potapova O, Pizer ES \& Gorospe M 2003 Role of the RNA-binding protein HuR in colon carcinogenesis. Oncogene 22 7146-7154.

Lopez de Silanes I, Galban S, Martindale JL, Yang X, Mazan-Mamczarz K, Indig FE, Falco G, Zhan M \& Gorospe M 2005 Identification and functional outcome of mRNAs associated with RNA-binding protein TIA-1. Molecular and Cellular Biology 25 9520-9531.

Mazan-Mamczarz K, Kuwano Y, Zhan M, White EJ, Martindale JL, Lal A \& Gorospe M 2009 Identification of a signature motif in target mRNAs of RNA-binding protein AUF1. Nucleic Acids Research 37 204-214.

Melck A, Masoudi H, Griffith OL, Rajput A, Wilkins G, Bugis S, Jones SJ \& Wiseman SM 2007 Cell cycle regulators show diagnostic and prognostic utility for differentiated thyroid cancer. Annals of Surgical Oncology 14 3403-3411.

Moraes KC, Quaresma AJ, Maehnss K \& Kobarg J 2003 Identification and characterization of proteins that selectively interact with isoforms of the mRNA binding protein AUF1 (hnRNP D). Biological Chemistry 384 25-37.

Nagaoka K, Tanaka T, Imakawa K \& Sakai S 2007 Involvement of RNA binding proteins AUF1 in mammary gland differentiation. Experimental Cell Research 313 2937-2945. 
Park-Lee S, Kim S \& Laird-Offringa IA 2003 Characterization of the interaction between neuronal RNA-binding protein HuD and AU-rich RNA. Journal of Biological Chemistry 278 39801-39808.

Polyak K, Lee MH, Erdjument-Bromage H, Koff A, Roberts JM, Tempst P \& Massague J 1994 Cloning of p27Kip1, a cyclin-dependent kinase inhibitor and a potential mediator of extracellular antimitogenic signals. Cell 78 59-66.

Reed MF, Zagorski WA, Howington JA, Zilfou JT \& Knudsen ES 2006 Inhibition of retinoblastoma tumor suppressor activity by RNA interference in lung cancer lines. Annals of Thoracic Surgery 82 249-253.

Ross J 1995 mRNA stability in mammalian cells. Microbiological Reviews 59 423-450.

Sherr CJ 1996 Cancer cell cycles. Science 274 1672-1677.

Sherr CJ \& Roberts JM 1995 Inhibitors of mammalian G1 cyclin-dependent kinases. Genes and Development 9 1149-1163.

Somasundaram K, Zhang H, Zeng YX, Houvras Y, Peng Y, Zhang H, Wu GS, Licht JD, Weber BL \& El-Deiry WS 1997 Arrest of the cell cycle by the tumour-suppressor BRCA1 requires the CDK-inhibitor p21WAF1/CiP1. Nature 389 187-190.

Suswam EA, Nabors LB, Huang Y, Yang X \& King PH 2005 IL-1beta induces stabilization of IL- 8 mRNA in malignant breast cancer cells via the $3^{\prime}$ untranslated region: involvement of divergent RNA-binding factors HuR, KSRP and TIAR. International Journal of Cancer 113 911-919.

Wang S, Wuu J, Savas L, Patwardhan N \& Khan A 1998 The role of cell cycle regulatory proteins, cyclin D1, cyclin E, and p27 in thyroid carcinogenesis. Human Pathology 29 1304-1309.

Wang W, Caldwell MC, Lin S, Furneaux H \& Gorospe M 2000 $\mathrm{HuR}$ regulates cyclin A and cyclin B1 mRNA stability during cell proliferation. EMBO Journal 19 2340-2350.

Wang W, Martindale JL, Yang X, Chrest FJ \& Gorospe M 2005 Increased stability of the p16 mRNA with replicative senescence. EMBO Reports 6 158-164.

Xu N, Chen CY \& Shyu AB 2001 Versatile role for hnRNP D isoforms in the differential regulation of cytoplasmic mRNA turnover. Molecular and Cellular Biology 21 6960-6971.

Zhang W, Wagner BJ, Ehrenman K, Schaefer AW, DeMaria CT, Crater D, DeHaven K, Long L \& Brewer G 1993 Purification, characterization, and cDNA cloning of an AU-rich element RNA-binding protein, AUF1. Molecular and Cellular Biology 13 7652-7665.

Zhang L, Zhou W, Velculescu VE, Kern SE, Hruban RH, Hamilton SR, Vogelstein B \& Kinzler KW 1997 Gene expression profiles in normal and cancer cells. Science 276 1268-1272. 